\title{
USE OF PSYCHODIAGNOSTICS IN THE WORK OF A COACH
}

\author{
Valerii Malkin, Liudmila Rogaleva, Irina Mamaeva \\ Ural Federal University, Ekaterinburg, Russia
}

\begin{abstract}
Summary: The purpose of the study was to assess the effectiveness of the use of psycho-diagnostics in the practical work of the coach. In total, the study involved 7 coaches ( 3 women and 4 men, the average age was about 24.5), young athletes (158 people, the average age of athletes was 13.5 years.) The received facts confirm the importance of information received with the help of psycho-diagnostics about motivation and the objectives of the young athletes, the relationship in the sports team, as well as the attitude of young athletes to the upcoming competitions. It is proved that the coach's work with young athletes on the basis of data of psycho-diagnostics allows improving the organization of psychological work with young athletes.
\end{abstract}

Key words: psychodiagnostics, coach, sportsmen.

\section{Introduction}

The leading role in the management of the training process belongs to the coach, because the success of his/her sportsmen largely depends on his professionalism, ability to analyze and predict the behavior of the athletes during the competition.

Psychological testing has long established itself as an effective tool in the work of a sports psychologist (Giessen, 1973; Khanin, 1980; $\quad$ Malkin, 2008; Gorbunov, 2006). But it could be no less effective tool in the coaching, helping him/her to properly evaluate and predict the behavior of athletes in extreme conditions, to make adjustments in its precompetitive preparation, based on objective data, to build individual work with athletes, specifically to solve specific problems in the psychological preparation of an athlete and in team management.

Psychological diagnostics is particularly important in the work of the trainer on the stage of advanced sport specialization, in the period of adolescence of young athletes, as it is just this period when a stable system of personal qualities of young athletes is formed, and important mental mechanisms of regulation of activity, such as motivation, personal orientation, self-esteem and level of claims, are being laid.

Despite the obvious benefits of the use of psycho-diagnostics in sport, currently in Russia it is not actually used (Rodionov, 2004; Malkin et. al., 2015; Sivitsky et. al.,2014). This is due, firstly, to the fact that in most sport schools there is no position of a sports psychologist, and secondly, due to the unwillingness of the coaches to use the available psychological tools in their work.

In our opinion, this leads to low efficiency of the psychological work of coaches with young athletes. As a result, the athletes acquire different psychological complexes and problems which either cause considerable psychological difficulties in later stages of a sports career, or lead to withdrawal of talented athletes from sports. Therefore, we consider, it is necessary to introduce effective and affordable methods of psycho-diagnostics in the practice of the trainer's work in compliance with ethical standards.

The aim of the study was to evaluate the efficiency of the methods of psycho-diagnostics in the work of a coach.

\section{Methods}

The first phase of work was devoted to defining psycho-diagnostic Toolkit for trainers. Selection of methods was carried out in accordance with the basic approaches to psychological support for young sportsmen, and also taking into account the age characteristics, by selection of the most significant personality indicators, which are critical for psychological readiness of young athletes to sport activities, and as a consequence, to the achievement of sports mastery.

As a result, basing on the method of deduction and induction, we have allocated three units of psycho-diagnostic instrumentation which the train- 
er can use for specific psychological information about the athletes.

Unit 1 - motivational. We have included In the motivational unit psycho-diagnostic techniques that allow coaches to obtain more objective information about how the young athlete applies to sports, about the prevalence of external or internal motivation, about sports target of young athletes and their attitude to training and competition process.

Unit 2 - social. The social block includes techniques that can help the coach better understand interpersonal relationships in the team, satisfaction with the atmosphere in the group; can help obtain information about positive or negative role of leaders. These data are extremely important because they allow the coach to make a prediction about how solid is the team and on what is the psychological background of training and competition of young athletes. In addition, data on the social block can help the coach to develop an adequate strategy of building relationships with the athletes.

Unit 3 - personal. Methods of this unit focus on the diagnosis of personality indicators of young athletes, as well as their readiness for the upcoming competitions. The obtained data can help the coach to predict psychological problems and difficulties in young athletes, which can reduce the results of their competition; better understand the personal characteristics of young athletes, their level of confidence or insecurity, and therefore more adequately carry out psychological work with athletes, picking up such forms and methods of influence, which provide the formation of mental readiness of young athletes for competition.

At the second stage there was arranged and conducted the research on the use of methods of diagnostics in the work of the coach. The study involved 5 coaches in such sports as football, figure skating, synchronized skating, climbing, athletics, badminton. In the whole there were involved 7 coaches, 3 women and 4 men, the average age 24.5 , with a master's degree, and their 158 athletes, the average age of athletes 13, 5 years. Organization of work of the trainer on the use of the methods of psycho-diagnostics was based on the following algorithm: the coach got a brief instruction on conducting psycho-diagnostics with athletes, then conducted the testing and data analysis and then developed a program of work with young athletes. In the beginning of the study and before the end of it parents were informed about participation in the study and guaranteed the confidentiality of information.

The coach could consult a sports psychologist during his/her work. At the end of the performed work (within a year), the trainer conducted a re-test. In the process of the work, the coaches also evaluated the informativeness and usefulness of used methods of psychological diagnostics for practice. In this regard, in this article, we will focus on the consideration of those methods which were highly appreciated by the trainers. Firstly, it is the questionnaire "Motivation of sports activities" (modified version Teipel et al., 2007), which includes 31 possible answers to the question "I exercise because...". Athletes were asked to rate on a scale from 1 to 6 answers indicating either an external motivation ("many of my friends play sports", "parents convince me the benefits of sports", I could be famous (get recognition) or internal ("the pleasure is all mine", "I particularly like this sport", "I would like to (a) check what I can achieve, what I'm capable of"). Secondly, the questionnaire "The goals of young athletes in sport" in which athletes indicated those goals that they target in the near future, and thirdly, methods of Fidler of emotional-psychological climate in the team (Fetiskin, et al., 2002), fourth, the technique of attitude to the upcoming competition" (Khanin, 1980).

\section{Results and Discussion}

Analyzing the results of the questionnaire "Motivation of sports activities" coaches were able to see how the motives of sports in young athletes are poorly differentiated. They could also get a better understanding of the causes of changes in the motivations of young athletes under the influence of external and internal factors. All coaches recognized the need to pay more attention to the development of the motivation of athletes, taking into consideration both common and individual data. As the basis of this work there was used a motivational strategy for the inclusion of young athletes in sports (Malkin et al., 2008). Deliberate coaching during the year led to positive changes in the motivation of young athletes, primarily in the direction of formation of internal motives over external, orientation on development of their abilities. These results are shown in table 1 . 
Table 1. The motives of sports in young athletes (\%).

\begin{tabular}{|l|l|l|}
\hline Questions & Study $\mathbf{~}$ & Study 2 \\
\hline I enjoy doing sports & 5.2 & 5.9 \\
\hline I like to win & 4.7 & 5.2 \\
\hline I would like to check what I can achieve, & 4.3 & 5.8 \\
what I'm capable of & & \\
\hline I like our team & 4.7 & 5.6 \\
\hline Doing sports, I can earn money & 5.4 & 4.2 \\
\hline I could be famous (obtain recognition) & 6.6. & 5.0 \\
\hline I would like to make good money in the field of sports & 5.5 & 4.5 \\
\hline I like the attention of the public & 4.2 & 4.5 \\
\hline I like to overcome challenges set by the coach & 5.1 & 5.7 \\
\hline I want to be successful & 5.7 & 5.9 \\
\hline parents and coach convinced me in the benefits of sports & 6,2 & 5.3 \\
\hline
\end{tabular}

No less important for coach became the results of independent work, factors which, in the opinion of the questionnaire "The goals of young athletes in young athletes, assist in the achievement of high sport", which are presented in table 2 .

Table 2. The attitude of young athletes to the training process

How many times a week you must exercise to achieve good result?

\begin{tabular}{|l|l|l|}
\hline & Study 1 & Study 2 \\
\hline 4 times a week & $20 \%$ & $10 \%$ \\
\hline 5 times a week & $50 \%$ & $60 \%$ \\
\hline 6 times a week & $30 \%$ & $30 \%$ \\
\hline To train additionally on your own & $80 \%$ & $100 \%$ \\
\hline \multicolumn{2}{|l|}{ What can hinder you to achieve results? } \\
\hline
\end{tabular}

\begin{tabular}{|l|l|l|}
\hline & Study 1 & Study 2 \\
\hline Laziness & $20 \%$ & $10 \%$ \\
\hline Complacency & $20 \%$ & $10 \%$ \\
\hline The lack of will & $10 \%$ & $10 \%$ \\
\hline The lack of self-control & $30 \%$ & $10 \%$ \\
\hline $\begin{array}{l}\text { Unforeseen external factors (ill- } \\
\text { ness, study, etc.) }\end{array}$ & $20 \%$ & $60 \%$ \\
\hline What is ming tochieve the gol? &
\end{tabular}

What is missing to achieve the goal?

\begin{tabular}{|c|c|c|}
\hline & Study 1 & Study 2 \\
\hline Physical conditions & $20 \%$ & $60 \%$ \\
\hline Technical preparation & $40 \%$ & $20 \%$ \\
\hline Other & $40 \%$ & $20 \%$ \\
\hline \multicolumn{3}{|c|}{$\begin{array}{l}\text { What factors are necessary for achievement of high } \\
\text { sports results? }\end{array}$} \\
\hline & Study 1 & Study 2 \\
\hline To work over "I cannot" & $60 \%$ & $20 \%$ \\
\hline $\begin{array}{l}\text { To comply with the training re- } \\
\text { gime }\end{array}$ & $0 \%$ & $80 \%$ \\
\hline
\end{tabular}

All coaches noted the receipt of new information about preferences of young athletes to the training process, to the number of ongoing training, to the sports results. The data received by the coaches could help them make adjustments in the organization and methodology of the training activities to revise the program of work with young athletes and to expand the forms and methods of organization of independent work of young athletes. The work conducted by the trainers contributed to the awareness of the young athletes of the need for independence training to achieve the goals; also there has been a reorientation of the views of young athletes from the principle "work through "cannot" to the compliance with the training regime; and the revaluation of its internal settings which may prevent to achieve sports results.

When using the methods to study the atmosphere in the team, the coaches were able to realistically assess various aspects of interaction of young athletes (table 3).

\section{Table 3 - Dynamics of indicators of emotional and psychological climate}

\begin{tabular}{|l|l|l|}
\hline & Study 1 & Study 2 \\
\hline compassion, understanding & 2,6 & 3,8 \\
\hline $\begin{array}{l}\text { the joy for the success of team- } \\
\text { mates }\end{array}$ & 3,8 & 6,3 \\
\hline $\begin{array}{l}\text { personal initiative is encouraged, } \\
\text { freedom for the organization of } \\
\text { team affairs }\end{array}$ & 2,6 & 4,1 \\
\hline there is a sense of cohesion, unity & 3,0 & 6,7 \\
\hline a friendly relationship & 3,6 & 6,9 \\
\hline
\end{tabular}

According to coaches, the interpersonal relationships of young athletes and the influence of these 
relationships is the most difficult task, so the data obtained in the course of psycho-diagnostics, enabled them, first, to clarify if their point of view and objective information are the same, and more confidently manage the interaction of athletes and to influence children's team. The willingness of the trainers to conduct targeted psychological and pedagogical work on the incorporation and formation of the appropriate relations in children's sports team contributed to the strengthening of positive relationships in teams and team building. Coaches also noted the importance of methods "Attitude to the upcoming competition" for psychological preparation of young athletes for competition

Data for this method are presented in table 4.

Table 4 Study of the attitude of young athletes to competition

\begin{tabular}{|l|l|l|}
\hline Parameter & \multicolumn{2}{|l|}{ Average point } \\
\hline & Study 1 & Study 2 \\
\hline Confidence & 4,4 & 6,2 \\
\hline $\begin{array}{l}\text { The perception of the capabilities } \\
\text { of the opponent }\end{array}$ & 7,2 & 4,7 \\
\hline $\begin{array}{l}\text { The desire to participate and the } \\
\text { importance of competition }\end{array}$ & 6,6 & 6,8 \\
\hline $\begin{array}{l}\text { The subjective perception of as- } \\
\text { sessment from the coach, parents, } \\
\text { team members }\end{array}$ & 3,8 & 4,8 \\
\hline
\end{tabular}

The results of this technique allowed the coach to quickly obtain information about the perception of athletes of the upcoming competitions, if it is necessary to quickly adjust the setup of both individual athletes and the team as a whole. The coaches noted that one of the characteristic trends for all young athletes is that when comparing their own capabilities with the capabilities of opponents they evaluate themselves often below opponents, which greatly affects their emotional state during the competition. In this regard, the trainers specially paid more attention to the problem of the formation of an adequate perception of the rivals. The trainers called important the information about "the desire to perform in the upcoming competition", since at low values on the scale, as a result of fear or uncertainty, the probability of reducing the results of the competition is obvious. Therefore, the figure as an indication of the confidence of the athlete before the competition requires from the coach an individual approach when working with athletes. The coaches were convinced on the basis of the obtained data that the desire to compete in young athletes was at a high enough level, but the idea of them, of their readiness to perform in the competition was different in different athletes. Some athletes may assume that the coach or parents don't believe in them and their successful performance, others on the contrary think that the coach is confident in them.

Basing on these data, coaches were able to reconsider their behavior before, during and after the competition. They were able to successfully adjust to improper installation by the parents before the start, to develop their methods of influence, increase the sense of confidence in young athletes during the competition. Thus, before competition coaches were more concentrated on the strengths of the athletes, refused to criticism, fixing attention not on winning, but on performing the tasks. Positive dynamics of the results according to the method in the second phase of the study confirmed the accuracy of the coach work.

\section{Conclusion}

The study proved that the use of methods of psycho-diagnostics in the work of the coach allows, on the one hand, getting useful and important information and in a more focused way organize psychological work with young athletes. We can recommend these methods of psycho-diagnostics for broader use in the practice of coaches, as well as the collaborative work of coach and sports psychologist. Further work in this direction involves testing these methods of psycho-diagnostics at different stages of the sports career.

\section{References}

Carron, A., Widmeyer, W.N., Brawley, L.R. (1985). The development of an Instrument to Assess Cohesion in Sport teams: The Group Environment Questionnaire. Journal of Sport Psychology, 7, pp. 244-266

Fetiskin, N.P., Kozlov, V.V., Manuylov, G.M. (2002). Methods for assessing the psychological atmosphere in the team (according to A. F. Fidler). Socio-psychological diagnosis of personality development and small groups. Publishing house of the Institute of Psychotherapy. Moscow, pp.190-191

Giessen, L.D. (1973). Psychology and psychohygiene in sports. Sport. Moscow.

Gorbunov, G.D. (2006). Psychopedagogy of Sports. Sport. Moscow.

Khanin, Yu. (1980). Psychology of communication in sports. Physical culture and Sport. Moscow.

Malkin, V. R. (2008). Management psychological preparation in sports. Physical culture and Sport. Moscow. 
Malkin, V.R., Rogaleva, L.N. (2015). Sport is Psychology. Sport. Moscow.

Malkin V., Rogaleva L. (2008). Motivation strategy as factor devolepment person of the school children. International Journal of Psychology, 43, 1. 3-4. p. 323.

Martens, R. (2004). Successful Coaching. Human Kinetics. Champaign, IL.

Rodionov, A.V. (2004). Psychology of Physical Education and Sports. Academic project. Moscow.

Rogaleva L., Malkin V. (2016). System of psychological work in sport. International Journal of Psychology, 51, S1, p.1114

Sivitsky, V. G., Melnik and Silich E. V. (2014). Monitoring of psychological readiness of athletes through the use of complex computer programs. Information-analytical bulletin. Vol. 19. The results of execution of tasks of state programs of development of physical culture and sports, innovative projects of BSUPC. Minsk, pp. 277-303. Teipel, D., Kemper R. (2007). Specific Motivational Aspects in Female Soccer Referees. 12 European Congress of Sport Psychology 4-9 september 2007, Halkidiki, Greece, Book of abstract, p.362.

Williams, J. M. (Ed.). (2006). Applied sport psychology: Personal growth to peak performance (5th ed.). McGraw-Hill, Boston.

Weinberg, R.S. Gould D. (2011). Foundations of sport and exercise psychology. Human Kinetics. Champaign, IL.

Valerii Malkin, PhD, professor. Ural Federal University, Institute of Physical Education, Sport and Youth Policy, 14 Kominterna st., Ekaterinburg, 620078, Russia.

E-mail: ValeryMalkin@yandex.ru 